Published in final edited form as:

Curr Opin Cell Biol. 2006 February ; 18(1): 79-85.

\title{
Asymmetric Spindle Positioning
}

\author{
Erin K. McCarthy and Bob Goldstein \\ Biology Department, University of North Carolina at Chapel Hill, Chapel Hill, NC 27599-3280
}

\section{Summary}

When a spindle is positioned asymmetrically in a dividing cell, the resulting daughter cells are unequal in size. Asymmetric spindle positioning can be driven by regulated forces that can pull or push a spindle. The physical and molecular mechanisms that can position spindles asymmetrically have been studied in a number of systems, and some themes have begun to emerge from recent research. Recent work in budding yeast has presented a model for how cytoskeletal motors and cortical capture molecules can function in orienting and positioning a spindle. The temporal regulation of microtubule-based pulling forces that move a spindle has been examined in one animal system. Although the spindle positioning force generators have not been identified in most animal systems, the forces have been found to be regulated by both PAR polarity proteins and by G-protein signaling pathways in more than one animal system.

\section{Introduction}

When a mitotic spindle becomes positioned asymmetrically within a cell, cell division results in daughter cells that are unequal in size. Such asymmetry in spindle position occurs commonly, for example in budding yeast mitotic divisions and in countless developmental cell divisions (Figure 1) [1]. In animal development, asymmetric divisions like these often have an additional, important role in unequally partitioning cell-fate determinants. Asymmetry in size of cells alone is likely to be important to partition such determinants precisely [2] and to allow large stem cells to divide repeatedly without becoming depleted of cytoplasm [3]. Here, we discuss the physical forces that asymmetrically position spindles, the molecular machinery that may generate and regulate these forces, and checkpoints that can monitor spindle position in some systems, highlighting some recent findings that have shed light on molecular mechanisms.

\section{Forces that asymmetrically position a spindle}

In a symmetrically dividing cell, the spindle is located at the center of the cell through mechanisms that may passively position it [4]. Certain cell shapes alone can dictate asymmetric division planes [5,6], but in most cases of asymmetric division, it is likely that forces are actively exerted on a spindle from one or more specialized sites on the cell cortex. To assess the regional sources of pulling and pushing forces that act on parts of the spindle, researchers have cut spindles in half, or eliminated one side of a spindle, and followed the immediate movement of the experimentally isolated spindle parts [7-11]. Such experiments have been performed to date on only one type of asymmetrically dividing cell, the relatively large

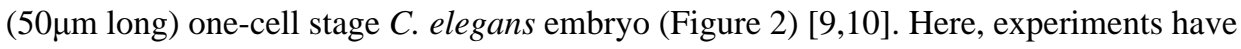
demonstrated that microtubule pulling forces are pervasive throughout the cell cortex, and that these pulling forces are stronger on one side of the cell -- at the posterior cortex -- causing the spindle to shift from the center of the embryo towards the posterior. These posterior pulling forces are generated early in mitosis, even before the spindle is completely assembled. Spindles are not shifted this early in the cell cycle, however, due to astral microtubules that tether the spindle to the anterior cortex until near the time that spindle assembly is completed [10]. Determining whether pulling forces dominate similarly in other asymmetrically dividing cells awaits experiments in other systems. 


\section{Force-generating mechanisms}

\section{Molecular motors}

Early studies in Chaetopterus oocytes demonstrated the presence of a unique attachment site to which the spindle migrates when experimentally pulled away from the cortex [12], and morphologically unique sites in the cortex of certain sea urchin embryonic cells toward which spindles move [13]. Whether movement in either case is driven by molecular motors or by other mechanisms such as microtubule depolymerization [14] during continuous attachment to a cortical site is not clear. These studies have been influential, however, in suggesting that regions of the cortex may be specialized for spindle attachment and spindle pulling.

Molecular motors that walk along microtubules or actin filaments can contribute to spindle positioning directly, by generating a pulling or pushing force, or indirectly by transporting cargo proteins that contribute to spindle positioning. Budding yeast is one of the most wellstudied cases of motors functioning directly to position a spindle $[15,16]$. Spindle orientation is initially dependent on myosin, which functions through interactions with plus-end microtubule binding proteins Kar9 and Bim1 to move microtubules along actin cables to the bud tip. Later, during anaphase, spindle positioning is dependent on dynein, which binds microtubule plus ends and guides the spindle through the neck and into the daughter cell (Figure $3)$.

The posterior cell of the two-cell stage C. elegans embryo may undergo spindle rotation through attachment of microtubules to a cortical capture site containing an enrichment of actin, dynein and components of the dynactin complex, recruited to the cell division remnant of the previous one-cell stage division [17-19]. The use of conditional dynein mutants suggests that dynein is essential for spindle positioning in this cell, but is dispensable for spindle positioning at the one cell stage [20], although an observed decrease in rate of dynein-dependent events and enrichment of dynein near centrosomes in these experiments suggests that these disrupted dynein motors might still function in walking along a microtubule more slowly than normal, and might inefficiently release once at the minus end of the microtubule [20].

Meiotic divisions in animal eggs are extreme forms of asymmetric division, producing tiny polar bodies and large egg cells. Recent work on C. elegans and Xenopus meiotic division has identified motors required to position spindles -- a microtubule-based motor in C. elegans, and an actin-based motor in Xenopus [21,22]. Yang and colleagues found a role for a kinesin motor in C. elegans meiotic spindle position. Meiotic spindles in C. elegans have defects in translocation to the cortex in oocytes lacking a Kinesin-I homolog or its associated light chains, or a putative cargo protein that has been shown to interact with both the kinesin light chains and a heterochromatin binding protein in a yeast two-hybrid screen [23]. Meiotic spindles in C. elegans oocytes lack centrosomes and astral microtubules, and the potential link between Kinesin-I and the meiotic spindle suggests a model in which the Kinesin-I motor activity might directly translocate the spindle to the cortex. Xenopus meiotic spindles are positioned adjacent to the cortex by the interaction of microtubules and F-actin [24]. Recent work has found that an unconventional myosin, Myo10, interacts directly with microtubules [21]. Disruption of Myo10 function results in defects in nuclear positioning, an event that normally requires microtubules [24,21], and in spindle structure and rotation, which normally requires actin filaments [21]. These results suggest a role for Myo10 in linking the actin and microtubule networks for their function in nuclear and spindle positioning.

Other motors function indirectly in spindle positioning, by transporting other motors or nonmotor proteins that affect spindle movement. Recent studies in budding yeast have shown that Kip2 kinesin plays roles in transporting dynein and Bik1, a CLIP-170-related microtubulestabilizing protein, to the plus ends of astral microtubules, from which dynein is presumably 
delivered to the cortex [25,26]. In asymmetrically dividing Drosophila neuroblasts, dynein has been shown to be required for apical localization of inscuteable mRNA, and thus Insc protein, which plays a role in both spindle orientation and segregation of cell fate determinants [27, 28]. Localization of basally-localized proteins required for asymmetric division in this system requires the actin-based motors myosin VI and myosin II [29,30].

\section{Cortical capture of microtubules}

A cortical capture mechanism might perform several jobs during cell division: microtubules that interact with the cortical capture site might orient the spindle along a specific axis, continued interaction with the site might maintain proper orientation, and cortical proteins that depolymerize microtubules might function in generating pulling forces that may move a spindle to an asymmetric position.

In budding yeast, astral microtubules are captured at the bud tip cortex and function in positioning the spindle along the mother-bud axis [15]. Several recent studies have focused on understanding cortical capture in budding yeast and identifying proteins that may regulate microtubule dynamics at the capture site. Kar9 functions in linking microtubule plus ends, via Bim1, to Myo2, which guides microtubules along actin cables towards the bud tip. Live-cell imaging experiments in budding yeast have distinguished the roles of Kar9 and actin-associated Bud6 in microtubule cortical capture-Kar9 functions in delivery of microtubules along actin cables into the bud, while Bud6 functions in securing microtubule capture at the bud tip [31]. It has also been shown that subunits of the type I phosphatase complex regulate the interaction of microtubules at the bud cortex, via Bud14, to maintain spindle position within the bud neck [32]. Other recent work has shown how an asymmetry in spindle pole bodies may contribute to cortical capture- the cyclin dependent kinase $\mathrm{Cdc} 28$ and cyclin B Clb4 are localized to the bud-ward spindle pole body (SPB), and are translocated to the plus ends of astral microtubules in a manner dependent on Kar9 $[33,34]$. This complex regulates the interaction of microtubules with the bud cortex, although how Cdc28-Clb4 modifies cortically-bound microtubules remains unknown.

\section{Microtubule dynamics and length}

Some asymmetric cell divisions may depend directly on microtubule dynamics to position a spindle. It is possible, for example, that by locally regulating the stability of microtubules, the duration of interaction with microtubule motors may be controlled. It is also possible that locally stable microtubules that reach the cortex but do not interact with motors may occlude movement of a spindle. By imaging microtubules at the cortex in early C. elegans embryos, Labbé et al [35] found that microtubules reaching the anterior cortex are more stable than those reaching the posterior cortex. Whether this difference is required to move the spindle asymmetrically is not yet known. Recent work in C. elegans has also examined the effects of specific mutations in tubulin isoforms on spindle positioning — certain dominant mutations of these tubulin isoforms affect microtubule dynamics [36] as well as spindle positioning events [37-39], but how altered microtubule dynamics affect spindle positioning is unclear.

Microtubule length must also be regulated in order to correctly position a spindle, and this is especially apparent during the meiosis-to-mitosis transition in animal development. The $C$. elegans homologs of the microtubule-severing protein katanin are required to keep microtubules short during meiosis but must be downregulated in mitosis to allow the growth of a larger spindle that fills the one-cell stage embryo [40-43]. Early C. elegans embryos lacking MBK-2, a member of the Dyrk family of protein kinases, have short microtubules and defects in spindle positioning [44]. This phenotype is rescued by knockdown of katanin, suggesting that MBK-2 protein normally functions to downregulate katanin, thereby controlling spindle size during mitosis [44]. Other proteins that affect microtubule length, 
independent of the katanin pathway, include the Doublecortin-related kinase ZYG-8 [45] as well as the TAC-1/ZYG-9 complex, members of the TACC family and the associated XMAP215 family, respectively [46-48].

Spindle positioning can occur by means of asymmetries in microtubule aster size, of which the most studied example is Drosophila neuroblasts. In these cells, the spindle is shifted basally, where the centrosome and associated microtubules are small compared to the apical centrosome and its microtubules (Figure 3) [49]. In an extreme case of spindle pole asymmetry, one-cell stage embryos of the freshwater oligochaete Tubifex divide asymmetrically with only one spindle pole containing the microtubule-nucleating protein gamma-tubulin and astral microtubules [50].

\section{Regulators of force-generating mechanisms Polarity establishment}

C. elegans has been a well-studied model for polarity establishment (Figure 3). Recent research has aimed at understanding how polarity-establishing proteins function in controlling asymmetric spindle positioning. PAR proteins are essential for downstream events that may affect spindle positioning; these downstream events include the regulation of microtubule stability at the cortex [35], the generation of pulling forces [9,10], and the asymmetric localization of other proteins required for spindle positioning such as LET-99 and GPR-1/2 [51-54]. Drosophila neuroblasts also localize a PAR protein complex to the apical cortex of the dividing cell [28]. It is important, then, in other asymmetrically dividing cell types, to determine if similar mechanisms are used in polarity establishment. Recent work in mouse oocytes has revealed the localization of homologs of PAR6 and PAR3 to a cortical actin cap near the meiotic spindle [55,56]. Polarity establishment in animal cells may not always be regulated by the PAR proteins, however. HAM-1, for example, is localized asymmetrically and is required for asymmetric division in C. elegans neuroblasts [57].

\section{G-protein signaling}

G-protein signaling is a major regulator of asymmetric spindle positioning in several systems including C. elegans and Drosophila. G protein signaling acts downstream of the PAR proteins, affecting spindle orientation without affecting the localization of cell fate determinants [58]. Spindle positioning is affected through the non-receptor-dependent G-alpha/G-beta-gamma complex when a regulator of this pathway induces the exchange of GDP for GTP on G-alpha, followed by the separation of G-beta-gamma from G-alpha [58]. Either of these subunits, or both, may promote downstream signaling. Recent work in C. elegans embryos has identified a role for RIC-8 as a guanine exchange factor, to stimulate GTP binding to and activation of a G-alpha protein to induce pulling forces [59-61], in addition to being required for the cortical localization of a second G-alpha protein [62]. Another regulator of G-protein signaling, RGS-7, functions in stimulating the hydrolysis of GTP-G-alpha to GDP-G-alpha, modulating those forces [61]. While the PAR proteins are required for generating an asymmetry in pulling forces [9,10], G-protein signaling is required for generating strong pulling forces on both sides of the cell [52,53], indicating that PAR proteins differentially regulate forces that are strictly dependent on $G$ protein signaling.

In Drosophila as in C. elegans, G-protein signaling functions in regulating the spindle orientation downstream of cell fate determinant segregation $[63,28]$. Neuroblasts lacking a functional G-beta-gamma complex cannot correctly orient spindles [63]. The activity of this G-protein signaling pathway is regulated by Pins (Partner of Inscuteable) and Loco (Locomotion defect), which localize apically along with G-alpha [64]. Pins and Loco function synergistically as guanine nucleotide dissociation inhibitors to facilitate to generation of free 
G-beta-gamma [65,64], while Loco may have an additional function as a GTPase-activating protein to regulate the equilibrium of GDP-G-alpha and GTP-G-alpha [64].

How G-protein signaling causes an asymmetry in microtubule pulling forces is unknown in asymmetrically dividing cells. Recent work in mammalian cells has, however, suggested a model. Mammalian Pins, called LGN, links cortical G-alpha to NuMA, a microtubule binding protein [66]. When either G-alpha or YFP:LGN is overexpressed, spindles in these cells have pronounced oscillations that are NuMA-dependent [66], suggesting that these proteins regulate spindle positioning forces. It will be interesting to see if similar mechanisms are used in asymmetrically dividing cells, such as in C. elegans and Drosophila, where the LGN homologs GPR-1/2 and Pins become localized asymetrically [52,53].

\section{Monitoring Asymmetric Spindle Positioning}

In budding yeast, spindle positioning is monitored, ensuring accurate chromosome segregation. The budding yeast spindle position checkpoint delays activation of the mitotic exit network (MEN) in cells with mispositioned spindles, via activation of the Bub2-Bfa1 complex [15]. Activation of this signaling pathway is triggered by changes in MEN protein dynamics at spindle poles upon penetration of the daughter-bound spindle pole into the bud [67]. Recent work by two groups describes Kin4 kinase as part of this monitor, inhibiting MEN signaling in cells with mispositioned spindles $[68,69]$. The MEN signaling pathway ultimately triggers anaphase onset by regulating Cdc14 release from the nucleolus. Prior to this, a small wave of Cdc14 release occurs via the FEAR network (Cdc-fourteen early anaphase release), which triggers early anaphase events. The FEAR network has recently been demonstrated to play a role, via Cdc14, in ensuring proper nuclear position during anaphase [70]. Fission yeast cells, although they divide symmetrically, monitor spindle positioning by a checkpoint that also regulates anaphase onset timing [71-73]. Whether or not spindle position is monitored in animal cells or in other organisms is not yet clear.

\section{Conclusions}

The movement of a spindle to an eccentric location is a complex process requiring motor activities that act at specific times in a cell. The examples cited here provide some glimpses of partial mechanisms by which this may occur. It will be interesting to determine to what extent these mechanisms function similarly in other systems. In addition, it will be interesting to see how the mechanisms that control positioning in asymmetric divisions are similar or different to those that function in symmetrically dividing cells.

\section{Acknowledgements}

We thank K. Bloom and A. Brand for helpful comments on this manuscript, and J. Molk, K. Bloom, and A. Brand for images. Our research on asymmetric spindle positioning is supported by NIH grant R01 GM68966.

\section{References}

1. Lillie F. The organization of the egg of Unio, based on a study of its maturation, fertilization, and cleavage. J Morph 1901;17:227-292.

2. Whittaker JR. Acetylcholinesterase development in extra cells caused by changing the distribution of myoplasm in ascidian embryos. J Embryol Exp Morphol 1980;55:343-354. [PubMed: 7373203]

3. Watt FM, Hogan BL. Out of Eden: stem cells and their niches. Science 2000;287:1427-1430. [PubMed: 10688781]

4. Wilson, EB. The Cell in Development and Heridity. 3. New York: The Macmillan Compony; 1925.

5. Harris AK, Gewalt SL. Simulation testing of mechanisms for inducing the formation of the contractile ring in cytokinesis. J Cell Biol 1989;109:2215-2223. [PubMed: 2808525] 
6. Rappaport R, Rappaport BN. Cleavage in conical sand dollar eggs. Dev Biol 1994;164:258-266. [PubMed: 8026628]

7. Aist JR, Berns MW. Mechanics of chromosome separation during mitosis in Fusarium (Fungi imperfecti): new evidence from ultrastructural and laser microbeam experiments. J Cell Biol 1981;91:446-458. [PubMed: 7309791]

8. Aist JR, Liang H, Berns MW. Astral and spindle forces in PtK2 cells during anaphase B: a laser microbeam study. J Cell Sci 1993;104(Pt 4):1207-1216. [PubMed: 8314902]

9. Grill SW, Gonczy P, Stelzer EH, Hyman AA. Polarity controls forces governing asymmetric spindle positioning in the Caenorhabditis elegans embryo. Nature 2001;409:630-633. [PubMed: 11214323]

10. Labbe JC, McCarthy EK, Goldstein B. The forces that position a mitotic spindle asymmetrically are tethered until after the time of spindle assembly. J Cell Biol 2004;167:245-256. [PubMed: 15492042]

11. Tolic-Norrelykke IM, Sacconi L, Thon G, Pavone FS. Positioning and elongation of the fission yeast spindle by microtubule-based pushing. Curr Biol 2004;14:1181-1186. [PubMed: 15242615]

12. Lutz DA, Hamaguchi Y, Inoue S. Micromanipulation studies of the asymmetric positioning of the maturation spindle in Chaetopterus sp oocytes: I Anchorage of the spindle to the cortex and migration of a displaced spindle. Cell Motil Cytoskeleton 1988;11:83-96. [PubMed: 3191533]

13. Dan K. Studies on unequal cleavage in sea urchins. Develop, Growth and Differ 1979;21:527-535.

14. Lombillo VA, Stewart RJ, McIntosh JR. Minus-end-directed motion of kinesin-coated microspheres driven by microtubule depolymerization. Nature 1995;373:161-164. [PubMed: 7816099]

15. Pearson CG, Bloom K. Dynamic microtubules lead the way for spindle positioning. Nat Rev Mol Cell Biol 2004;5:481-492. [PubMed: 15173827]

16. Huisman SM, Segal M. Cortical capture of microtubules and spindle polarity in budding yeast where's the catch? J Cell Sci 2005;118:463-471. [PubMed: 15673685]

17. Hyman AA. Centrosome movement in the early divisions of Caenorhabditis elegans: a cortical site determining centrosome position. J Cell Biol 1989;109:1185-1193. [PubMed: 2768338]

18. Waddle JA, Cooper JA, Waterston RH. Transient localized accumulation of actin in Caenorhabditis elegans blastomeres with oriented asymmetric divisions. Development 1994;120:2317-2328. [PubMed: 7925032]

19. Skop AR, White JG. The dynactin complex is required for cleavage plane specification in early Caenorhabditis elegans embryos. Curr Biol 1998;8:1110-1116. [PubMed: 9778526]

20. Schmidt DJ, Rose DJ, Saxton WM, Strome S. Functional analysis of cytoplasmic dynein heavy chain in Caenorhabditis elegans with fast-acting temperature-sensitive mutations. Mol Biol Cell 2005;16:1200-1212. [PubMed: 15616192]

21. Weber KL, Sokac AM, Berg JS, Cheney RE, Bement WM. A microtubule-binding myosin required for nuclear anchoring and spindle assembly. Nature 2004;431:325-329. [PubMed: 15372037]

22. Yang HY, Mains PE, McNally FJ. Kinesin-1 mediates translocation of the meiotic spindle to the oocyte cortex through KCA-1, a novel cargo adapter. J Cell Biol 2005;169:447-457. [PubMed: 15883196]

23. Li S, Armstrong CM, Bertin N, Ge H, Milstein S, Boxem M, Vidalain PO, Han JD, Chesneau A, Hao T, et al. A map of the interactome network of the metazoan C. elegans. Science 2004;303:540-543. [PubMed: 14704431]

24. Gard DL, Cha BJ, Roeder AD. F-actin is required for spindle anchoring and rotation in Xenopus oocytes: a re-examination of the effects of cytochalasin B on oocyte maturation. Zygote 1995;3:1726. [PubMed: 7613871]

25. Sheeman B, Carvalho P, Sagot I, Geiser J, Kho D, Hoyt MA, Pellman D. Determinants of S. cerevisiae dynein localization and activation: implications for the mechanism of spindle positioning. Curr Biol 2003;13:364-372. [PubMed: 12620184]

26. Carvalho P, Gupta ML Jr, Hoyt MA, Pellman D. Cell cycle control of kinesin-mediated transport of Bik1 (CLIP-170) regulates microtubule stability and dynein activation. Dev Cell 2004;6:815-829. [PubMed: 15177030]

27. Hughes JR, Bullock SL, Ish-Horowicz D. Inscuteable mRNA localization is dynein-dependent and regulates apicobasal polarity and spindle length in Drosophila neuroblasts. Curr Biol 2004;14:19501956. [PubMed: 15530398] 
28. Wodarz A. Molecular control of cell polarity and asymmetric cell division in Drosophila neuroblasts. Curr Opin Cell Biol. 2005

29. Barros CS, Phelps CB, Brand AH. Drosophila nonmuscle myosin II promotes the asymmetric segregation of cell fate determinants by cortical exclusion rather than active transport. Dev Cell 2003;5:829-840. [PubMed: 14667406]

30. Petritsch C, Tavosanis G, Turck CW, Jan LY, Jan YN. The Drosophila myosin VI Jaguar is required for basal protein targeting and correct spindle orientation in mitotic neuroblasts. Dev Cell 2003;4:273-281. [PubMed: 12586070]

31. Huisman SM, Bales OA, Bertrand M, Smeets MF, Reed SI, Segal M. Differential contribution of Bud6p and Kar9p to microtubule capture and spindle orientation in S. cerevisiae. J Cell Biol 2004;167:231-244. [PubMed: 15492045]

32. Knaus M, Cameroni E, Pedruzzi I, Tatchell K, De Virgilio C, Peter M. The Bud14p-Glc7p complex functions as a cortical regulator of dynein in budding yeast. Embo J 2005;24:3000-3011. [PubMed: 16107882]

33. Maekawa H, Usui T, Knop M, Schiebel E. Yeast Cdk1 translocates to the plus end of cytoplasmic microtubules to regulate bud cortex interactions. Embo J 2003;22:438-449. [PubMed: 12554645]

34. Maekawa H, Schiebel E. Cdk1-Clb4 controls the interaction of astral microtubule plus ends with subdomains of the daughter cell cortex. Genes Dev 2004;18:1709-1724. [PubMed: 15256500]

35. Labbe JC, Maddox PS, Salmon ED, Goldstein B. PAR proteins regulate microtubule dynamics at the cell cortex in C. elegans. Curr Biol 2003;13:707-714. [PubMed: 12725727]

36. Wright AJ, Hunter CP. Mutations in a beta-tubulin disrupt spindle orientation and microtubule dynamics in the early Caenorhabditis elegans embryo. Mol Biol Cell 2003;14:4512-4525. [PubMed: 12937270]

37. Ellis GC, Phillips JB, O'Rourke S, Lyczak R, Bowerman B. Maternally expressed and partially redundant beta-tubulins in Caenorhabditis elegans are autoregulated. J Cell Sci 2004;117:457-464. [PubMed: 14702387]

38. Phillips JB, Lyczak R, Ellis GC, Bowerman B. Roles for two partially redundant alpha-tubulins during mitosis in early Caenorhabditis elegans embryos. Cell Motil Cytoskeleton 2004;58:112-126. [PubMed: 15083533]

39. Lu C, Mains PE. Mutations of a redundant alpha-tubulin gene affect Caenorhabditis elegans early embryonic cleavage via MEI-1/katanin-dependent and -independent pathways. Genetics 2005;170:115-126. [PubMed: 15781712]

40. Mains PE, Kemphues KJ, Sprunger SA, Sulston IA, Wood WB. Mutations affecting the meiotic and mitotic divisions of the early Caenorhabditis elegans embryo. Genetics 1990;126:593-605. [PubMed: 2249759]

41. Clandinin TR, Mains PE. Genetic studies of mei-1 gene activity during the transition from meiosis to mitosis in Caenorhabditis elegans. Genetics 1993;134:199-210. [PubMed: 8514128]

42. Srayko M, Buster DW, Bazirgan OA, McNally FJ, Mains PE. MEI-1/MEI-2 katanin-like microtubule severing activity is required for Caenorhabditis elegans meiosis. Genes Dev 2000;14:1072-1084. [PubMed: 10809666]

43. Kurz T, Pintard L, Willis JH, Hamill DR, Gonczy P, Peter M, Bowerman B. Cytoskeletal regulation by the Nedd8 ubiquitin-like protein modification pathway. Science 2002;295:1294-1298. [PubMed: 11847342]

44. Pang KM, Ishidate T, Nakamura K, Shirayama M, Trzepacz C, Schubert CM, Priess JR, Mello CC. The minibrain kinase homolog, mbk-2, is required for spindle positioning and asymmetric cell division in early C. elegans embryos. Dev Biol 2004;265:127-139. [PubMed: 14697358]

45. Gonczy P, Bellanger JM, Kirkham M, Pozniakowski A, Baumer K, Phillips JB, Hyman AA. zyg-8, a gene required for spindle positioning in $\mathrm{C}$. elegans, encodes a doublecortin-related kinase that promotes microtubule assembly. Dev Cell 2001;1:363-375. [PubMed: 11702948]

46. Bellanger JM, Gonczy P. TAC-1 and ZYG-9 form a complex that promotes microtubule assembly in C. elegans embryos. Curr Biol 2003;13:1488-1498. [PubMed: 12956950]

47. Le Bot N, Tsai MC, Andrews RK, Ahringer J. TAC-1, a regulator of microtubule length in the C. elegans embryo. Curr Biol 2003;13:1499-1505. [PubMed: 12956951] 
48. Srayko M, Quintin S, Schwager A, Hyman AA. Caenorhabditis elegans TAC-1 and ZYG-9 form a complex that is essential for long astral and spindle microtubules. Curr Biol 2003;13:1506-1511. [PubMed: 12956952]

49. Kaltschmidt JA, Davidson CM, Brown NH, Brand AH. Rotation and asymmetry of the mitotic spindle direct asymmetric cell division in the developing central nervous system. Nat Cell Biol 2000;2:712. [PubMed: 10620800]

50. Ishii R, Shimizu T. Unequal first cleavage in the Tubifex egg: involvement of a monastral mitotic apparatus. Develop Growth Differ 1995;37:687-701.

51. Tsou MF, Hayashi A, DeBella LR, McGrath G, Rose LS. LET-99 determines spindle position and is asymmetrically enriched in response to PAR polarity cues in C. elegans embryos. Development 2002;129:4469-4481. [PubMed: 12223405]

52. Colombo K, Grill SW, Kimple RJ, Willard FS, Siderovski DP, Gonczy P. Translation of polarity cues into asymmetric spindle positioning in Caenorhabditis elegans embryos. Science 2003;300:19571961. [PubMed: 12750478]

53. Gotta M, Dong Y, Peterson YK, Lanier SM, Ahringer J. Asymmetrically distributed C. elegans homologs of AGS3/PINS control spindle position in the early embryo. Curr Biol 2003;13:10291037. [PubMed: 12814548]

54. Srinivasan DG, Fisk RM, Xu H, van den Heuvel S. A complex of LIN-5 and GPR proteins regulates $\mathrm{G}$ protein signaling and spindle function in C elegans. Genes Dev 2003;17:1225-1239. [PubMed: 12730122]

55. Vinot S, Le T, Maro B, Louvet-Vallee S. Two PAR6 proteins become asymmetrically localized during establishment of polarity in mouse oocytes. Curr Biol 2004;14:520-525. [PubMed: 15043819]

56. Duncan FE, Moss SB, Schultz RM, Williams CJ. PAR-3 defines a central subdomain of the cortical actin cap in mouse eggs. Dev Biol 2005;280:38-47. [PubMed: 15766746]

57. Frank CA, Hawkins NC, Guenther C, Horvitz HR, Garriga G. C. elegans HAM-1 positions the cleavage plane and regulates apoptosis in asymmetric neuroblast divisions. Dev Biol 2005;284:301310. [PubMed: 15979607]

58. Gotta M, Ahringer J. Distinct roles for Galpha and Gbetagamma in regulating spindle position and orientation in Caenorhabditis elegans embryos. Nat Cell Biol 2001;3:297-300. [PubMed: 11231580]

59. Afshar K, Willard FS, Colombo K, Johnston CA, McCudden CR, Siderovski DP, Gonczy P. RIC-8 is required for GPR-1/2-dependent Galpha function during asymmetric division of C. elegans embryos. Cell 2004;119:219-230. [PubMed: 15479639]

60. Couwenbergs C, Spilker AC, Gotta M. Control of embryonic spindle positioning and Galpha activity by C. elegans RIC-8. Curr Biol 2004;14:1871-1876. [PubMed: 15498497]

61. Hess HA, Roper JC, Grill SW, Koelle MR. RGS-7 completes a receptor-independent heterotrimeric $\mathrm{G}$ protein cycle to asymmetrically regulate mitotic spindle positioning in C. elegans. Cell 2004;119:209-218. [PubMed: 15479638]

62. Afshar K, Willard FS, Colombo K, Siderovski DP, Gonczy P. Cortical localization of the G\{alpha\} protein GPA-16 requires RIC-8 function during C. elegans asymmetric cell division. Development. 2005

63. Izumi Y, Ohta N, Itoh-Furuya A, Fuse N, Matsuzaki F. Differential functions of G protein and BazaPKC signaling pathways in Drosophila neuroblast asymmetric division. J Cell Biol 2004;164:729_ 738. [PubMed: 14981094]

64. Yu F, Wang H, Qian H, Kaushik R, Bownes M, Yang X, Chia W. Locomotion defects, together with Pins, regulates heterotrimeric G-protein signaling during Drosophila neuroblast asymmetric divisions. Genes Dev 2005;19:1341-1353. [PubMed: 15937221]

65. Schaefer M, Shevchenko A, Knoblich JA. A protein complex containing Inscuteable and the Galphabinding protein Pins orients asymmetric cell divisions in Drosophila. Curr Biol 2000;10:353-362. [PubMed: 10753746]

66. Du Q, Macara IG. Mammalian Pins is a conformational switch that links NuMA to heterotrimeric G proteins. Cell 2004;119:503-516. [PubMed: 15537540]

67. Molk JN, Schuyler SC, Liu JY, Evans JG, Salmon ED, Pellman D, Bloom K. The differential roles of budding yeast Tem1p, Cdc15p, and Bub2p protein dynamics in mitotic exit. Mol Biol Cell 2004;15:1519-1532. [PubMed: 14718561] 
68. D'Aquino KE, Monje-Casas F, Paulson J, Reiser V, Charles GM, Lai L, Shokat KM, Amon A. The protein kinase Kin4 inhibits exit from mitosis in response to spindle position defects. Mol Cell 2005;19:223-234. [PubMed: 16039591]

69. Pereira G, Schiebel E. Kin4 kinase delays mitotic exit in response to spindle alignment defects. Mol Cell 2005;19:209-221. [PubMed: 16039590]

70. Ross KE, Cohen-Fix O. A role for the FEAR pathway in nuclear positioning during anaphase. Dev Cell 2004;6:729-735. [PubMed: 15130497]

71. Gachet Y, Tournier S, Millar JB, Hyams JS. A MAP kinase-dependent actin checkpoint ensures proper spindle orientation in fission yeast. Nature 2001;412:352-355. [PubMed: 11460168]

72. Oliferenko S, Balasubramanian MK. Astral microtubules monitor metaphase spindle alignment in fission yeast. Nat Cell Biol 2002;4:816-820. [PubMed: 12360293]

73. Tournier S, Gachet Y, Buck V, Hyams JS, Millar JB. Disruption of astral microtubule contact with the cell cortex activates a Bub1, Bub3, and Mad3-dependent checkpoint in fission yeast. Mol Biol Cell 2004;15:3345-3356. [PubMed: 15146064] 
Figure 1.

Asymmetric spindle positioning in a mussel, a drawing based on staining of embryos with textile dyes used at the time by cytologists [1]. A number of theories of how spindles are positioned asymmetrically already existed by this time. 

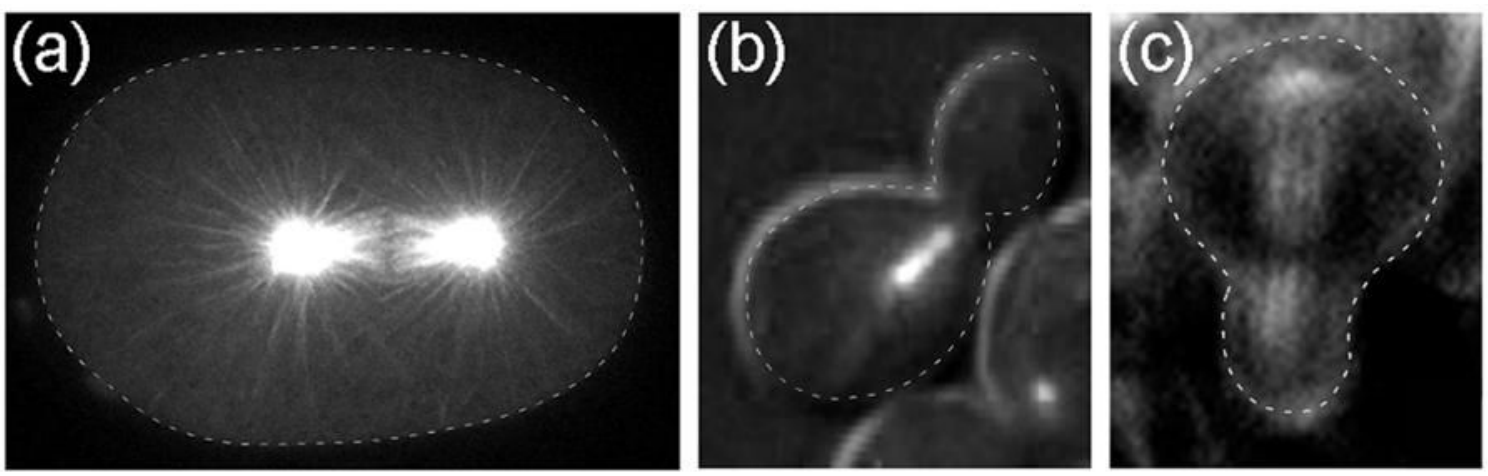

Figure 2.

The mitotic spindle is positioned asymmetrically in early C. elegans embryos (a), budding yeast cells (b), and Drosophila neuroblasts (c). Live-cell imaging of cells expressing tubulin:GFP or tau:GFP have allowed the analysis of changes in spindle position, orientation, structure, size, and dynamics. Budding yeast image provided by J. Molk and K. Bloom. Drosophila image provided by A. Brand. 

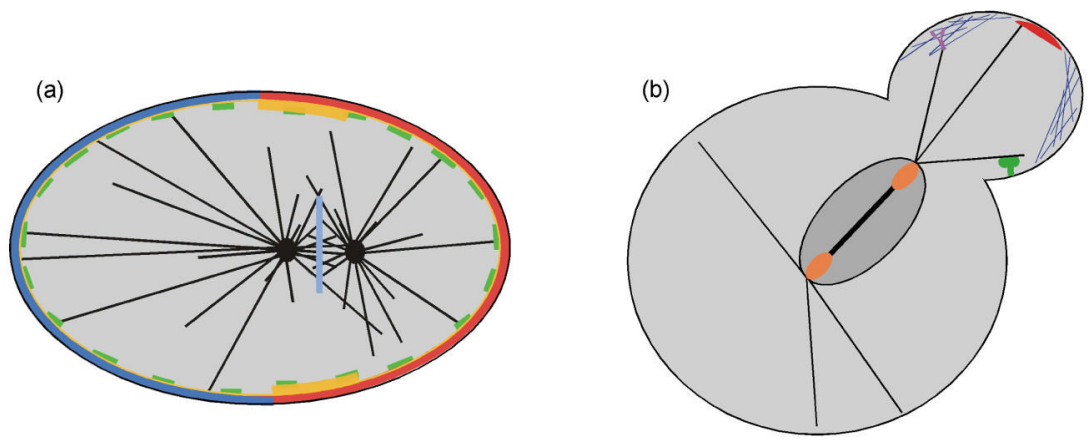

(c)

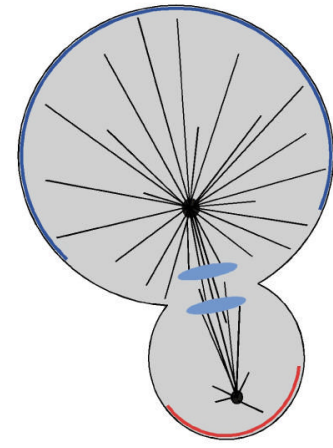

Figure 3.

The mitotic spindle is positioned asymmetrically in these cell divisions. (a) In the C. elegans one-cell stage embryo, the mitotic spindle is positioned close to the posterior cortex. This is dependent on the presence of cortical proteins (PAR-3 is blue, PAR-2 is red, LET-99 is orange) that regulate force generators, which might be dynein patches localized at the cortex (green). (b) In budding yeast, the spindle is oriented when myosin (purple) binds plus ends of microtubules to direct them to cortical proteins at the bud tip cortex (red), which may provide a pulling force. Dynein (green) positions the spindle into the bud neck during anaphase through interactions of astral microtubules at the cortex. (c) In Drosophila neuroblasts, the spindle is asymmetric during anaphase when the apical microtubules are able to grow longer than basal microtubules. Cortical complexes that are required for spindle orientation and cell fate determination include the PAR/aPKC and Pins/G-alpha complexes, which are localized apically (blue), and Miranda, Prospero, and Numb, which are localized basally (red). 